\title{
Administration of Zinc with Paroxetine Improved the Forced Swim Test Behavioral Pattern of Treated Mice in Acute and Sub-Acute Study
}

\author{
Hesham El Refaey ${ }^{1 *}$, Hasan S. Al Amri², Abdelkader E. Ashour ${ }^{3}$, Atallah F. Ahmed ${ }^{4}$ \\ ${ }^{1}$ Pharmacology Department, College of Pharmacy, King Khalid University, Abha, Saudi Arabia \\ ${ }^{2}$ Psychiatry Department, College of Medicine, King Khalid University, Abha, Saudi Arabia \\ ${ }^{3}$ Department of Pharmacology and Toxicology, College of Pharmacy, King Saud University, Abha, Saudi Arabia \\ ${ }^{4}$ Department of Pharmacognosy, College of Pharmacy, King Saud University, Abha, Saudi Arabia \\ Email: " heshamelrefaey@hotmail.com
}

Received 24 March 2015; accepted 4 July 2015; published 7 July 2015

Copyright (C) 2015 by authors and Scientific Research Publishing Inc.

This work is licensed under the Creative Commons Attribution International License (CC BY).

http://creativecommons.org/licenses/by/4.0/

(c) ()) Open Access

\begin{abstract}
Despite progressive improvement in treating major depressive disorder (MDD), it remains mostly unresponsive to one antidepressant medication. Zinc is a brain highly abundant trace metal, a brain derived neurotrophic factor (BDNF) inducer, a modulator of synaptic plasticity and potent suppressor of the NMDA receptors. We proposed that co-administration of zinc with the antidepressants may represent a valuable regimen to improve the efficacy of these drugs. This work has been implemented to evaluate the behavioral changes of acute and sub-acute co-administration of zinc with Paroxtine in mice. Methods: The animals were injected intra-peritoneal with either Paroxtine $(20 \mathrm{mg} / \mathrm{kg}$ ) which was a selective serotonin reuptake inhibitor (SSRI), zinc sulfate (30 $\mathrm{mg} / \mathrm{kg}$ ) or Paroxtine in combination with zinc for one day and one week (once daily). The pattern of the animal behavior was assessed in the forced swim test (FST). Results and Discussion: The behavioral patterns of the animals in the FST include immobility, swimming and climbing. Successful antidepressant should decrease the immobility time with either increase in swimming and/or climbing behavior based on the drug pharmacological activity. Our results revealed a significant decrease of immobility and increase of swimming behavior indicating serotonin-dependent pharmacological activity of Paroxtine or zinc alone as well as in the animals treated with zinc in combination with Paroxtine. There was no significant difference in the animals' behavior between acute and sub-acute treatment with zinc or even upon its addition to paroxetine. Our data support the concept that co-administration of zinc may provide further antidepressant activity.
\end{abstract}

\footnotetext{
${ }^{*}$ Corresponding author.
}

How to cite this paper: El Refaey, H., Al Amri, H.S., Ashour, A.E. and Ahmed, A.F. (2015) Administration of Zinc with Paroxetine Improved the Forced Swim Test Behavioral Pattern of Treated Mice in Acute and Sub-Acute Study. Journal of Behavioral and Brain Science, 5, 213-220. http://dx.doi.org/10.4236/jbbs.2015.57022 
Zinc may offer additional clinical value particularly in geriatric patients or other populations where zinc level has shown dramatic decrease.

\section{Keywords}

Depression, Antidepressants, Paroxetine, Zinc

\section{Introduction}

Major depression disorder (MDD) is responsible for high morbidity in the overall population. It is an overwhelming illness that affects $17 \%$ of the population at some point in life, resulting in major social and economic consequences [1]. It is a chronic disorder, commonly characterized by relapses and recurrences. Suicide is estimated to be the cause of death in up to approximately $15 \%$ of individuals with MMD, and many other deleterious health-related effects have been recognized [2] [3]. Despite the overwhelming impact of depression, the available treatments are either not effective in many patients or have many adverse effects.

Paroxetine is an SSRI antidepressant. It is used to treat major depression, obsessive-compulsive disorder, panic disorder, social anxiety, and generalized anxiety disorder in adult outpatients [4]. In adults, the efficacy of paroxetine for depression is comparable to that of older tricyclic antidepressants, with fewer side effects and lower toxicity. Differences with newer antidepressants are subtler and mostly confined to side effects. It shares the common side effects and contraindications of other SSRIs, with high rates of nausea, somnolence, and sexual side effects [5]. Partial response and non-response to antidepressant medications are common problems. From 10\% - 30\% of depressed patients taking antidepressants are partially or totally resistant to the treatment [6] [7] and recurrence of depression while still taking medication can also occur [8].

In the geriatric population, there is a higher incidence of chronic MMD and many bear a nutritional deficiency component, either as a cause or as a result of illness issues. The trace elements, such as zinc and copper, are essential components of many metalloproteins and metalloenzymes and a deficiency of one of these elements could lead to an alteration of cellular function, particularly at the neuronal level [9]. Zinc is necessary for many enzymatic activities, DNA replication, transcription and protein synthesis. It is widely distributed in the whole body, but the brain (especially the hippocampus and cerebral cortex) has the highest zinc concentrations [10][12]. In the brain, all neurons bearing synaptic zinc are glutamatergic, indicating the significant importance of zinc in NMDA activities [13] [14]. Alterations in brain zinc homeostasis are associated with behavioral disturbances, such as anorexia, dysphoria, impaired learning and cognitive function and with some neurological disorders due to its potent inhibitory effect of the NMDA receptor complex [15] [16]. Zinc is implicated in the pathophysiology and therapy of depression [17] [18]. Also, zinc administration increases brain-derived neurotrophic factor (BDNF) gene expression in the rat brain [18] [19]. That feature correlates with the fact that chronic treatment with classical antidepressants increases BDNF [20] and induces neurogenesis [21] in rats. Moreover, zinc has been shown to modulate intracellular signaling cascades, such as mitogen-activated protein kinases (MAPKs), protein kinase C (PKC), protein tyrosine phosphatases (PTP), $\mathrm{Ca}^{2+} / \mathrm{calmodulin}^{2}$ activated protein kinase II (CaMK-II), participating in different cellular activities including proliferation, differentiation, and death [22].

Clinical observations demonstrated a reduced blood zinc level in the depressed patients [23]. Interestingly, this reduction was normalized only after successful antidepressant therapy [24]. Chronic antidepressant treatment elevates and redistributes zinc concentration in the rat hippocampus [25]. Chronic treatment with imipramine increases the potency of zinc to inhibit the NMDA receptor activity in the mouse cerebral cortex [26]. These alterations may lead to a reduction in the activity of the NMDA receptor complex. Zinc has been found active in the forced swimming test, commonly used for evaluation of antidepressant activity [27]. Moreover, zinc exhibits antidepressant-like effects in animal models of depression, such as chronic mild stress and olfactory bulbectomy models of depression [28].

Antidepressants do not act as direct mood enhancers and their effects are gradual and their neuronal and psychological benefits are dissociable and subtle. They are characterized by a delayed onset of action without noticeable clinical effects that have not seen before 3 - 4 weeks of treatment suggesting adaptive mechanisms in- 
duced by chronic use [29]. We were wondering if zinc administration would show a different onset of action either at the acute or the sub-acute level.

In this study, we used the forced swimming test in mice to investigate whether zinc influenced the antidepressant effects of selective serotonin reuptake inhibitor Parexotine (Pxt). We also studied the effects of combined administration of zinc and Pxt on spontaneous locomotor activity in mice.

\section{Materials and Methods}

All procedures were conducted according to the general Animal Care and Use Committee guidelines, and were approved by the Ethics Committee of the Pharmacology department, KKU. The experiments were carried out on male Albino Swiss mice (25 - 30 g). The animals were kept under a natural day-night cycle with free access to food and water. Each experimental group consisted of 12 animals. Zinc sulfate and Paroxetine hydrochloride were administered by $I P$ injection following the initial pre-swim test, three times approximately at 23.5, 7 and 1 $\mathrm{h}$ prior to the $5 \mathrm{~min}$ forced swim test in the acute study while in the sub-acute study, the animals received the treatment once daily for one week. Control animals received vehicle (saline).

\subsection{Forced Swimming Test}

The studies were carried out according to the method of Porsolt et al. [30]. Mice were dropped individually into glass cylinders (height $25 \mathrm{~cm}$, diameter $10 \mathrm{~cm}$ ) filled with water to a height of $10 \mathrm{~cm}$, (maintained at $23^{\circ} \mathrm{C}$ $25^{\circ} \mathrm{C}$ ), and animals were exposed to a pretest for $15 \mathrm{~min}, 24 \mathrm{~h}$ prior to the 5 -min swim test. The pretest facilitates the development of immobility during the test session and increases the sensitivity for detecting antidepressant behavioral effects. The animals were removed from the water, dried by the experimenter and placed in plastic cages with a heating pad. Behavioral scoring was performed according to Detke et al. [31] and during the 5 min test session three different behaviors were rated: 1) immobility—animals were judged to be immobile when it remained floating passively in the water; 2) swimming - rats were judged to be swimming if they were making active swimming motions, more than necessary to solely maintain their head above water; 3) climbing-mice were judged to be climbing when they were making active movements in and out of the water with their forepaws, usually directed against the walls.

\subsection{Locomotor Activity}

Locomotor activity was measured using photoresistor actometers (circular cages, $25 \mathrm{~cm}$ in diameter, two light sources, and two photoresistors). The animals were placed individually in an actometer for $10 \mathrm{~min}$. Activity was measured at 5-min intervals to characterize the dynamics of changes. The number of light beams crossed by an animal was recorded as the locomotor activity.

\subsection{Data Analysis}

The obtained data were evaluated by the one way analysis of variance (ANOVA), followed by Dunnett's multiple comparison test; $P<0.05$ was considered significant.

\section{Results}

Zinc sulfate at doses of 10, 20, 30 and $40 \mathrm{mg} / \mathrm{kg}$ (respectively) was tested in the forced swimming test in mice and in the locomotor activity test. Zinc significantly reduced the immobility time in the forced swimming test at the dose of 30 and $40 \mathrm{mg} / \mathrm{kg}$ and had no effect at doses of 10 and $20 \mathrm{mg} / \mathrm{kg}$ as presented in (Table 1). Therefore, the dose of $30 \mathrm{mg} / \mathrm{kg}$ was chosen for use in the studies of interaction of antidepressants with zinc.

In the acute study, zinc sulfate at a dose of $30 \mathrm{mg} / \mathrm{kg}$ was tested in the forced swimming test. Zinc significantly reduced the immobility time and increased the swimming behavior in the forced swimming test as shown in (Figure 1).

Also, Paroxetine administered alone at the dose of $20 \mathrm{mg} / \mathrm{kg}$ reduced the immobility time and increased the swimming (Figure 1). Combined administration of Prx $(20 \mathrm{mg} / \mathrm{kg})$ and zinc $(30 \mathrm{mg} / \mathrm{kg})$ in the acute study, induced statistically significant reduction of the immobility time in mice and increased the swimming durations as compared with either Prx or zinc treated animals as presented in Figure 1. On the other hand, combined administration of zinc with Prx had no effect on the locomotor activity in mice Figure 3. 


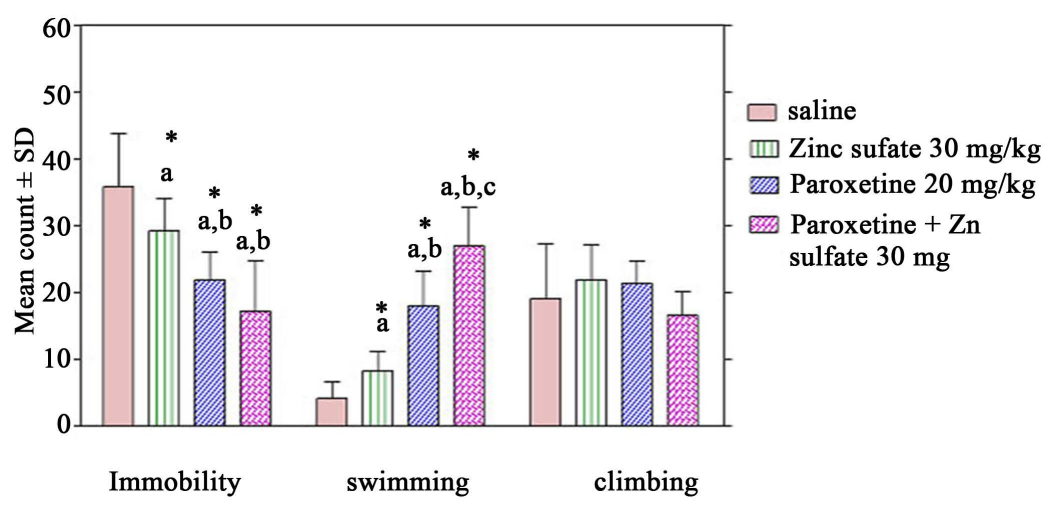

Figure 1. Effect of acute zinc sulfate (30 mg/kg) administration alone and/or in combination with paroxetine (20 mg/kg) for $24 \mathrm{~h}$ in the forced-swim test. Mice received their treatments three times following the initial 15 min pre-test swim, at 23.5, 7 and $1 \mathrm{~h}$ before the $5 \mathrm{~min}$ forced-swim test. Data are presented as mean \pm S.D. of total number of intervals spent in each specific behavior ( $\mathrm{N}=12$ per group), sampled every $5 \mathrm{sec}$, during a 5 min FST period. Significant differences within each behavior, as compared to (a) saline treatment; (b) $30 \mathrm{mg} / \mathrm{kg}$ zinc; (c) $20 \mathrm{mg} / \mathrm{kg}$ Paroxetine and (d) Paroxetine (20 mg/kg) + zinc $(30 \mathrm{mg} / \mathrm{kg})$, were determined by a 2-way multivariate ANOVA, followed by Dunnett's Multiple Comparison post test $(P<$ $0.05)$.

Table 1. Effect of different doses of acute zinc administration on the immobility time in the forced swim test.

\begin{tabular}{ccc}
\hline Immobility time & Dose & Compound \\
\hline $37.12 \pm 5.91$ & ---- & Saline \\
$34.70 \pm 7.32$ & $10 \mathrm{mg} / \mathrm{kg}$ & Zinc sulfate \\
$35.18 \pm 5.64$ & $20 \mathrm{mg} / \mathrm{kg}$ & Zinc sulfate \\
$29.42 \pm 4.16^{*}$ & $30 \mathrm{mg} / \mathrm{kg}$ & Zinc sulfate \\
$27.40 \pm 4.20^{*}$ & $40 \mathrm{mg} / \mathrm{kg}$ & Zinc sulfate \\
\hline
\end{tabular}

Zinc sulfate was administered one hour before the test. The values represent the mean $\pm \mathrm{SD}\left(\mathrm{N}=12\right.$ per group). $\left.{ }^{*} P<0.05\right)$ compared to saline treated animals by a 1-way ANOVA followed by Dunnett's Multiple Comparison post test.

In the sub-acute study, Zinc $(30 \mathrm{mg} / \mathrm{kg}$ ) significantly reduced the immobility time and increased the swimming activity in the forced swim test (Figure 2). Also, Paroxetine administered alone at the dose of $20 \mathrm{mg} / \mathrm{kg}$ reduced the immobility time and increased the swimming behavior durations as shown in (Figure 2). Combined administration of Prx $(20 \mathrm{mg} / \mathrm{kg})$ and zinc $(30 \mathrm{mg} / \mathrm{kg})$ in the sub-acute study, induced statistically significant reduction of the immobility time in mice and increased the swimming durations as compared with either Prx or zinc treated animals as shown in Figure 2. On the other hand, combined administration of zinc with Prx had no effect on the locomotor activity in mice, Figure 3.

The effects either zinc administration or Prx or combined administration of Prx and zinc on total duration of immobility of acute and sub-chronic studies in mice are shown in Table 2 . The results had shown no significant difference between acute and sub-acute administration of all treatments.

\section{Discussion}

Currently, several new classes of antidepressants are available, which act as selective biogenicamine reuptake inhibitors [32]. Unfortunately, commonly used antidepressant therapy is effective in only $60 \%-70 \%$ of patients and may produce a deleterious side effect [33]. Thus, the search for new and more effective therapeutic strategies represents one of the priorities for treatment of special populations as well as resistant patients.

In the present study, we demonstrate the behavioral effects of zinc sulfate either alone or in combination with paroxetine after acute and sub-acute administration in mice. Our data indicate that zinc administered once at the dose of $30 \mathrm{mg} / \mathrm{kg}$ reduces the immobility time of mice in the forced swimming test and increased the swimming activity. Concurrently, when zinc is given jointly with Prx. $(20 \mathrm{mg} / \mathrm{kg})$, a potent reduction in the immobility time is observed with concomitant increase in the swimming activity without change in the locomotor activity. Since 


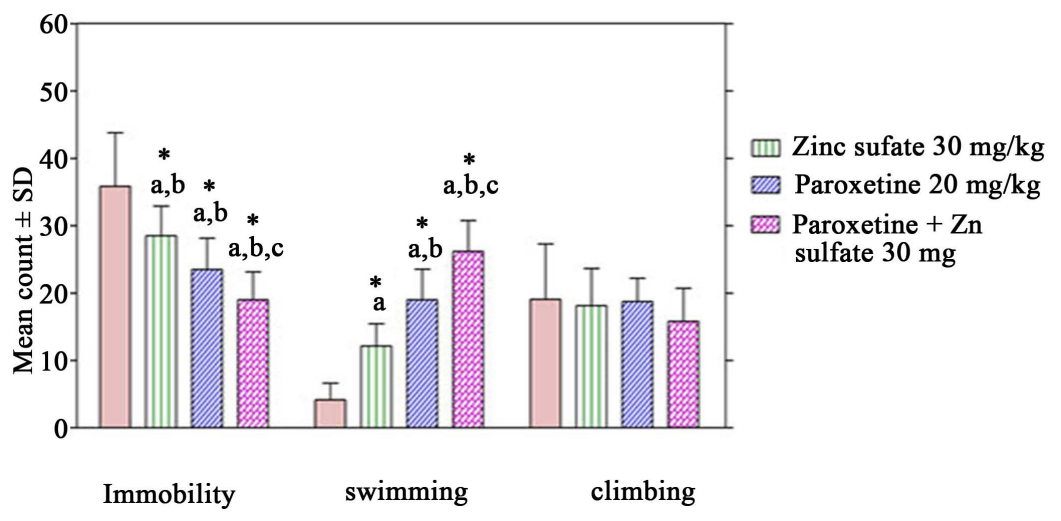

Figure 2. Effect of subacute zinc sulfate (30 mg/kg) administration alone and/or in combination with Paroxetine (20 mg/kg) for one week, once daily in the forced-swim test. Mice received the last dose 24 h before the 5 min forced-swim test. Data are presented as mean \pm S.D. of total number of intervals spent in each specific behavior $(\mathrm{N}=12$ per group), sampled every $5 \mathrm{sec}$, during a 5 min FST period. Significant differences within each behavior, as compared to (a) saline treatment; (b) 30 $\mathrm{mg} / \mathrm{kg}$ zinc; (c) $20 \mathrm{mg} / \mathrm{kg}$ Paroxetine and (d) Paroxetine (20 mg/kg) + zinc (30 mg/kg), were determined by a 2-way multivariate ANOVA, followed by Dunnett's Multiple Comparison post test $(P<0.05)$.

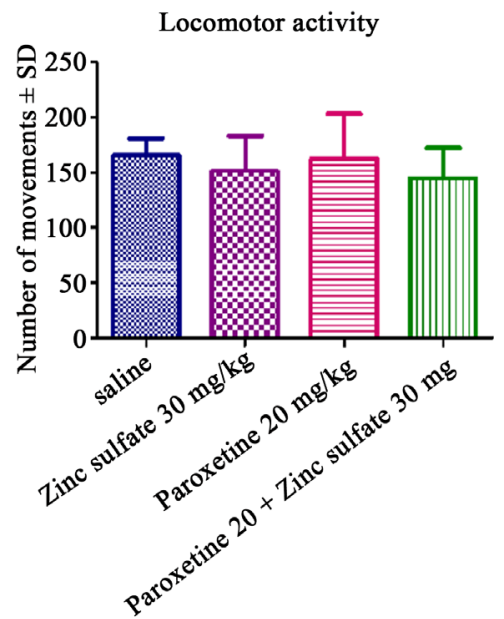

Figure 3. Effect of different treatments on locomotor activity in the open-field test. Mice received saline, Paroxetine (20 $\mathrm{mg} / \mathrm{kg}$ ) and $/$ or zinc sulfate (30 mg/kg) by IP injection prior to the $10 \mathrm{~min}$ open-field test. Data are presented as mean \pm S.D. number of crossings in the open-field test in response to saline or drug treatments. No significant difference was found between saline and zinc, paroxetine and zinc + paroxetine treated animals. Treated mice had no significant activity scores $\left({ }^{*} P<\right.$ 0.05) compared to saline treated animals by a 1-way ANOVA followed by Dunnett's Multiple Comparison post test.

Table 2. The effects of acute or sub-acute zinc sulfate $(30 \mathrm{mg} / \mathrm{kg})$ administration alone and/or in combination with Paroxetine $(20 \mathrm{mg} / \mathrm{kg})$ on the duration of immobility in mice. Data are presented as mean \pm S.D. of total number of intervals spent in immobile behavior ( $\mathrm{N}=12$ per group), sampled every $5 \mathrm{sec}$. Significant differences were determined by a 2-way multivariate ANOVA, followed by Dunnett’s Multiple Comparison post test $(P<0.05)$.

\begin{tabular}{cccc}
\hline Treatments immobility time & Paroxetine $(20 \mathrm{mg} / \mathrm{kg})$ & Zinc sulfate $(30 \mathrm{mg} / \mathrm{kg})$ & Paroxetine $(20 \mathrm{mg} / \mathrm{kg})+$ zinc sulfate $(30 \mathrm{mg} / \mathrm{kg})$ \\
\hline Acute $(24 \mathrm{hr})$ & $21.875 \pm 4.15$ & $29.25 \pm 4.80$ & $17.20 \pm 7.52$ \\
Sub-acute $(7$ days $)$ & $23.500 \pm 4.65$ & $28.50 \pm 4.40$ & $19.00 \pm 4.13$ \\
\hline
\end{tabular}

these treatments (Prx plus zinc) do not affect locomotor activity, the results indicate the synergistic effect of antidepressant-like activity by such combined treatments. These results confirmed that zinc produced an antidepressant-like effect and demonstrated a zinc induced enhancement of the antidepressant effect of Prx in the Porsolt's test without stimulation of locomotor activity. Recently, it was shown that chronic zinc administration increases the BDNF gene expression, which is the effect shared by most of clinically effective antidepressants. 
However, it is possible that other zinc doses and treatment studies might also cause the hippocampal BDNF alterations. Since zinc profoundly affects glutamate transmission, mainly by antagonizing the NMDA receptors [34], this glutamate-dependent mechanism is likely to be responsible for zinc-induced changes in BDNF gene expression. Previous data, of Trullas and Skolnick [35], demonstrated that the blockade of the NMDA receptor produced antidepressant-like action and enhanced the effect of antidepressant drugs [26].

Also, an increase in the swimming, but not climbing parameter of the mice FST observed following zinc administration indicates the serotonin pathway participation. Therefore, this data suggests that the antidepressant-like effect of zinc seems to be mediated through an interaction with the serotonergic rather than the noradrenergic system. This comes in partial agreement with the recent study of Cunha et al., 2008 showed the synergistic effects of zinc with not only "serotonergic" but also with "noradrenergic" and "dopaminergic" profile antidepressants in the mouse tail suspension test [36]. So, we can suggest that zinc may indirectly release 5HT, which in turn activates 5HT receptors as a part of the mechanism of antidepressant activity.

The present results show that zinc has an antidepressant effect that can be observed following its acute as well as sub-acute administration. This antidepressant action did not increase after repeated administration. It could be assumed that its effects have a serotonergic component that is also appearing from the first administration. The effect of zinc on swimming remains the same after 7 days of treatment. This may suggest that predominance of zinc effects as an NMDA antagonist over the other time consuming effects like BDNF induction that require chronic administration.

\section{Conclusion}

It could be concluded from this study that zinc possesses antidepressant activity. Zinc and Paroxetine combination may have a significant clinical application in psychiatric patients, particularly in geriatric patients or other populations where zinc level has shown dramatic decrease. Further studies are needed to assess the role of chronic zinc administration in augmenting the activity of antidepressants as well as its underlying mechanism.

\section{Acknowledgements}

The authors would like to extend their sincere appreciation to the Deanship of Scientific Research at King Saud University for its funding of this research through the Research Group Project no RGP-VPP-272.

\section{References}

[1] Yukihiko, S., Andrew, C.H., Shin, N., David, R.S. and Ronald, S.D. (2002) Brain-Derived Neurotrophic Factor Produces Antidepressant Effects in Behavioral Models of Depression. The Journal of Neuroscience, 8, 3251-3261.

[2] Schulz, R., Beach, S.R., Ives, D.G, Martire, L.M., Ariyo, A.A. and Kop, W.J. (2000) Association between Depression and Mortality in Older Adults: The Cardiovascular Health Study. Archives of Internal Medicine, 160, 1761-1768. http://dx.doi.org/10.1001/archinte.160.12.1761

[3] Ciechanowski, P.S., Katon, W.J. and Russo, J.E. (2005) The Association of Depression and Perceptions of Interpersonal Relationships in Patients with Diabetes. Journal of Psychosomatic Research, 58, 139-144. http://dx.doi.org/10.1016/j.jpsychores.2004.07.009

[4] Dechant, K.L. and Clissold, S.P. (1991) Paroxetine; a Review of Its Pharmacodynamic and Pharmacokinetic Properties, and Therapeutic Potential in Depressive Illness. Drugs, 41, 225-253. http://dx.doi.org/10.2165/00003495-199141020-00007

[5] Katzman, M.A. (2009) Current Considerations in the Treatment of Generalized Anxiety Disorder. CNS Drugs, 23, 103120. http://dx.doi.org/10.2165/00023210-200923020-00002

[6] Joffe, R.T., Levitt, A.J. and Sokolov, S.T. (1996) Augmentation Strategies. Journal of Clinical Psychiatry, 57, 25-31.

[7] United States Department of Health and Human Services, Public Health Service, Agency for Health Care Policy and Research (1993) Depression in Primary Care. Vol. 2, Treatment of Major Depression. Government Printing Office, AHCPR Publication No. 93-0550, Rockville.

[8] Fava, M., Rappe, S.M., Pava, J.A., Nierenberg, A.A., Alpert, J.E. and Rosenbaum, J.F. (1995) Relapse in Patients on Long-Term Fluoxetine Treatment. Journal of Clinical Psychiatry, 56, 52-55.

[9] Ikmekcioglu, C. (2001) The Role of Trace Elements for the Health of Elderly Individuals. Die Nahrung, 45, 309-316. http://dx.doi.org/10.1002/1521-3803(20011001)45:5<309::AID-FOOD309>3.0.CO;2-0

[10] Prasad, A.S., Fitzgerald, J.T., Hess, J.W., Kaplan, J., Pelen, F. and Dardenn, M. (1993) Zinc Deficiency in Elderly Pa- 
tients. Nutrition, 9, 218-224.

[11] Frederickson, C.J. (1989) Neurobiology of Zinc and Zinc-Containing Neurons. International Review of Neurobiology, 31, 145-238. http://dx.doi.org/10.1016/S0074-7742(08)60279-2

[12] Takeda, A. (2001) Zinc Homeostasis and Functions of Zinc in the Brain. Biometals, 14, 343-351. http://dx.doi.org/10.1023/A:1012982123386

[13] Takeda, A., Minami, A., Seki, Y. and Oku, N. (2003) Inhibitory Function of Zinc against Excitation of Hippocampal Glutamatergic Neurons. Epilepsy Research, 57, 169-174. http://dx.doi.org/10.1016/j.eplepsyres.2003.11.003

[14] Frederickson, C.J., Suh, S.W., Silva, D., Frederickson, C.J. and Thompson, R.B. (2000) Importance of Zinc in the Central Nervous System: The Zinc-Containing Neuron. The Journal of Nutrition, 130, 1471S-1483S.

[15] Nowak, G. and Szewczyk, B. (2002) Mechanisms Contributing to Antidepressant Zinc Actions. Polish Journal of Pharmacology, 54, 587-592.

[16] Kroczka, B., Brañski, P., Paucha, A., Pilc, A. and Nowak, G. (2001) Antidepressant-Like Properties of Zinc in Rodent Forced Swim Test. Brain Research Bulletin, 55, 297-300. http://dx.doi.org/10.1016/S0361-9230(01)00473-7

[17] Kroczka, B., Ziêba, A., Dudek, D., Pilc, A. and Nowak, G. (2000) Zinc Exhibits an Antidepressant-Like Effect in the Forced Swimming Test in Mice. Polish Journal of Pharmacology, 52, 403-406.

[18] Nowak, G., Legutkoa, B., Szewczyka, B., Pappa, M., Sanaka, M. and Pilc, A. (2004) Zinc Treatment Induces Cortical Brain-Derived Neurotrophic Factor Gene Expression. European Journal of Pharmacology, 492, 57-59. http://dx.doi.org/10.1016/j.ejphar.2004.03.038

[19] Nibuya, M., Morinobu, S. and Duman, R.S. (1995) Regulation of BDNF and trkB mRNA in Rat Brain by Chronic Electroconvulsive Seisure and Antidepressant Drug Treatments. The Journal of Neuroscience: The Official Journal of the Society for Neuroscience, 15, 7539-7547.

[20] Nibuya, M., Nestler, E.J. and Duman, R.S. (1996) Chronic Antidepressant Administration Increases the Expression of cAMP Response Element Binding Protein (CREB) in Rat Hippocampus. Journal of Neuroscience, 16, 2365-2372.

[21] Malberg, J.E. and Blendy, J.A. (2005) Antidepressant Action: To the Nucleus and beyond. Trends in Pharmacological Sciences, 26, 631-638. http://dx.doi.org/10.1016/j.tips.2005.10.005

[22] Beyersmann, D. and Haase, H. (2001) Functions of Zinc in Signaling, Proliferation and Differentiation of Mammalian Cells. Biometals, 14, 331-341. http://dx.doi.org/10.1023/A:1012905406548

[23] Maes, M., De Vos, N., Demedts, P., Wauters, A. and Neels, H. (1999) Lower Serum Zinc in Major Depression in Relation to Changes in Serum Acute Phase Proteins. The Journal of Affective Disorders, 56, 189-194. http://dx.doi.org/10.1016/S0165-0327(99)00011-7

[24] Schlegel-Zawadzka, M., Ziêba, A., Dudek, D., Krooeniak, M., Szymaczek, M. and Nowak, G. (2000) Effect of Depression and of Antidepressant Therapy on Serum Zinc Levels-A Preliminary Clinical Study. In: Roussel, A.M., Favier, A.E. and Anderson, R.A., Eds., Trace Elements in Man and Animals 10, Kluwer Academic Plenum Press, Dordrecht, 607-610.

[25] Takeda, A. (2000) Movement of Zinc and Its Functional Significance in the Brain. Brain Research Reviews, 34, 137-148. http://dx.doi.org/10.1016/s0165-0173(00)00044-8

[26] Skolnick, P., Legutko, B., Li, X. and Bymaster, F.P. (2001) Current Perspectives on the Development of Non-Biogenic Amine-Based Antidepressants. Pharmacological Research, 43, 411-423. http://dx.doi.org/10.1006/phrs.2000.0806

[27] Szewczyk, B., Kata, R. and Nowak, G. (2001) Rise in Zinc Affinity for the NMDA Receptor Evoked by Chronic Imipramine is Species Specific. Polish Journal of Pharmacology, 53, 641-645.

[28] Nowak, G., Szewczyk, B., Wieronska, J.M., Branski, P., Palucha, A., Pilc, A., Sadlik, K. and Piekoszewski, W. (2003) Antidepressant-Like Effects of Acute and Chronic Treatment with Zinc in Forced Swim Test and Olfactory Bulbectomy Model in Rats. Brain Research Bulletin, 61, 159-164. http://dx.doi.org/10.1016/S0361-9230(03)00104-7

[29] Harmer, C.J., Goodwin, G.M. and Cowen, P.J. (2009) Why Do Antidepressants Take So Long to Work? A Cognitive Neuropsychological Model of Antidepressant Drug Action. The British Journal of Psychiatry, 195, 102-108. http://dx.doi.org/10.1192/bjp.bp.108.051193

[30] Porsolt, R.D., Le Pichon, M. and Jalfre, M. (1977) Depression: A New Animal Model Sensitive to Antidepressant Treatments. Nature, 266, 730-732. http://dx.doi.org/10.1038/266730a0

[31] Detke, M.J., Rickels, M. and Lucki, I. (1995) Active Behaviors in the Rat Forced Swimming Test Differentially Produced by Serotonergic and Noradrenergic Antidepressants. Psychopharmacology, 121, 66-72. http://dx.doi.org/10.1007/BF02245592

[32] Stahl, S.M. (1997) Psychopharmacology of Antidepressants. Martin Duinz, London.

[33] Hollister, L.E. and Csernansky, J.G. (1990) Clinical Pharmacology of Psychotherapeutic Drugs. 3rd Edition, Churchill 
Livingstone, New York.

[34] Nowak, G. and Szewczyk, B. (2002) Mechanisms Contributing to Antidepressant Zinc Actions. Polish Journal of Pharmacology, 54, 587-592.

[35] Trullas, R. and Skolnick, P. (1990) Functional Antagonists at the NMDA Receptor Complex Exhibit Antidepressant Actions. European Journal of Pharmacology, 185, 1-10.

[36] Cunha, M.P., Machado, D.G., Bettino, L.E.B., Capra, J.C. and Rodrigues, A.L.S. (2008) Interaction of Zinc with Antidepressants in the Tail Suspension Test. Progress in Neuro-Psychopharmacology and Biological Psychiatry, 32, 19131920. http://dx.doi.org/10.1016/j.pnpbp.2008.09.006 